\title{
IMPACTOS DO CRÉDITO RURAL NA PRODUTIVIDADE DA TERRA E DO TRABALHO NAS REGIÕES BRASILEIRAS
}

\author{
Ricardo Bruno Nascimento dos Santos * \\ Marcelo José Braga ${ }^{\dagger}$
}

\begin{abstract}
Resumo
O objetivo deste trabalho é mensurar os impactos do crédito rural sobre a produtividade da terra e do trabalho nas grandes regiões brasileiras. A abordagem metodológica é baseada em modelo de restrição de crédito e no método do propensity score. Foram utilizados microdados do Censo Agropecuário de 2006. Os resultados mostram que o crédito não foi efetivo para aumentar a produtividade dos fatores no setor agrícola, exceto para a região nordeste do Brasil. Os resultados apontam para a necessidade de melhorias na política de crédito rural no Brasil.
\end{abstract}

Palavras-chave: Restrição de Crédito; Propensity Score Matching; Produtores Agrícolas; Microeconometria.

\begin{abstract}
The objective of this paper is to measure the impacts of farm credit on the productivity of the land and labor in Brazilian regions. The methodological approach is based on credit constraint model and propensity score matching. Micro data from the 2006 agricultural census are used. Results show that credit is not effective to improve the productivity of the factors in agricultural sector, except in the Northeast region. Finally, these results emphasize the need of improvements in farm credit policy of Brazil.
\end{abstract}

Keywords: Credit Rationing; Propensity Score Matching; Agricultural Households; Microeconometrics.

JEL classification: D13, P23, Q12, Q14

\footnotetext{
*Universidade Federal do Pará. E-mail: ricardobns@ufpa.br

† Universidade Federal de Viçosa. E-mail: mjbraga@ufv.br
} 


\section{Introdução}

O padrão produtivo que se estabeleceu na agricultura brasileira seguiu claramente a visão modernizante neoclássica, defendida por Schultz (1965), pelo fato de alterar a base tecnológica produtiva, sem alterar a estrutura agrária vigente. $\mathrm{O}$ autor indicava que a agricultura modernizada era capaz de dar uma grande contribuição para o crescimento econômico ao afirmar que "a agricultura pode ser um poderoso engenho do crescimento". Porém, para atingir o "engenho", era necessário investir na agricultura, gerando incentivos para orientar e recompensar os agricultores.

Os principais incentivos à agricultura viriam na disponibilização do crédito. O financiamento da agricultura ganhou maior importância a partir de 1965 com a criação do Sistema Nacional de Crédito Rural (SNCR), regulamentado então pelo Conselho Monetário Nacional (CMN).

Com sua criação, o SNCR passou a ser o principal instrumento de política agrícola brasileira. Conforme Leite (2001, p. 129), esse sistema promoveu o aumento da produtividade do setor agrícola, a consolidação dos complexos agroindustriais e cadeias agroalimentares, bem como a integração dos capitais agrários à orbita de valorização do capital financeiro. No entanto, segundo Comin \& Muller (1986, p. 3), o SNCR priorizava os setores agroindustriais, estabelecendo um novo patamar de custos de produção, criando barreiras a produtores potenciais, mas que, dada as novas condições, não permitia a entrada de micro e pequenos produtores rurais.

Nas décadas de 1970 e 1980, período em que o crédito era subsidiado ${ }^{1}$ e distribuído em função do tamanho dos estabelecimentos de propriedade dos tomadores, grande parcela do crédito rural foi direcionada aos grandes proprietários. Esse aspecto acabou sendo um fator gerador de restrição de crédito, principalmente para os pequenos agricultores, que não podiam oferecer as devidas garantias (geralmente terra).

Essas barreiras criaram uma série de restrições ao crédito para uma parcela significativa de agricultores, o que mais tarde seria agravado pela crise econômica de 1980 e, além das restrições aos produtores, observou-se também uma limitação do crédito nas grandes regiões brasileiras, fortemente concentrada nas regiões Sul e Sudeste. ${ }^{2}$

O conceito de restrição de crédito pode ser baseado de forma relativa, segundo Chaves et al. (2001, p. 55-56),no surgimento da comparação da demanda de um agente com a oferta de crédito à qual ele tem acesso. Um agente que não possui uma demanda por crédito não pode ser considerado um agente com restrição, porém aqueles que demandam o crédito e não conseguem possuem a restrição de crédito. Segundo Jappelli (1990), não é necessário que um agente demande crédito (e o tenha rejeitado) para ser considerada uma restrição, o simples medo de não obter crédito é uma restrição, pelo fato de esse agente ser considerado um consumidor desencorajado.

Assunção \& Alves (2007) apresentam evidências empíricas de que a restrição de crédito está presente no Brasil e que essa restrição afeta importantes decisões das famílias. Já Assunção \& Chein (2007), analisando especifica-

\footnotetext{
${ }^{1}$ Quando se fala em crédito subsidiado, refere-se ao fato de as taxas de juros praticadas durante o processo inflacionário serem menores que as taxas de inflação.

${ }^{2}$ Programas mais recentes como o Programa Nacional de Fortalecimento da Agricultura Familiar (PRONAF) procura corrigir esse problema com a concessão de crédito apenas a agricultores familiares. Entretanto, a análise deste programa não é escopo deste trabalho.
} 
mente famílias pertencentes a áreas rurais, encontraram evidências empíricas de que a restrição de crédito no meio rural é ativa no Brasil como um todo, assim como nas cinco macrorregiões analisadas pelos autores, sendo que a severidade da restrição de crédito foi maior na região Nordeste.

Com base nesses conceitos de restrição, em 2006, segundo o Censo Agropecuário, dos estabelecimentos agropecuários (excluindo-se assentamentos e a agroindústria) 33,48\% conseguiram algum tipo de crédito, sendo que a região Sul do Brasil apresentou o maior número de estabelecimentos rurais que obtiveram crédito (279.236) e a região Norte com o menor número de estabelecimentos (22.940).

O grande problema baseia-se no número de estabelecimentos que solicitaram o crédito e não obtiveram. No ano de 2006, dos estabelecimentos rurais que solicitaram crédito, $66,52 \%$ não o obtiveram, principalmente por motivos ligados a imperfeições de mercado. Alguns estudos internacionais ${ }^{3}$ indicam que a restrição ao crédito no meio rural limita a produção agrícola de forma substancial, ou seja, para países em desenvolvimento, a intervenção do governo pode trazer melhorias aos produtores. Considerando que o volume do crédito rural tem aumentado ao longo da década de 2000, a despeito da maior exigência sobre o crédito por parte dos bancos, vale questionar se a restrição ao crédito provoca mudanças significativas na produção agrícola e induzem melhorias na eficácia dos pequenos produtores rurais.

No caso do Brasil, avaliando o PRONAF, Magalhães (2006) mostraram para o estado de Pernambuco que os produtores que utilizaram o Pronaf foram menos eficazes que os produtores que não tiveram acesso ao programa. Em um estudo para o estado do Paraná, Magalhães \& Filizzola (2005), verificaram um efeito nulo do Pronaf sobre a produtividade da terra, no entanto, o valor da produção per capita foi positivo para as categorias B e C, indicando que a política do Pronaf foi efetiva para alguns produtores que tiveram acesso ao crédito.

Kageyama (2003) aplicou, para uma amostra de 1.994 domicílios de produtores rurais de 21 municípios e oito estados, o teste $t$ para igualdade de médias para beneficiários e não beneficiários do Pronaf. Em seus resultados, a autora verificou que a presença do programa promove aumentos na produtividade do trabalho e na produtividade da terra, no entanto, suas conclusões são feitas sem o pareamento da amostra, indicando que os dois grupos estudados (beneficiários ou não do Pronaf) são homogêneos, porém, ao conjunto de suas variáveis não foi aplicado um teste adequado para garantir que tais grupos sejam equiparáveis.

Entretanto, a grande questão por detrás dos estudos sobre crédito em todo o mundo refere-se aos problemas de informação. ${ }^{4} \mathrm{E}$ para o crédito rural no Brasil, esse elemento é crucial, pois, historicamente, a taxa de juros no mercado de crédito para o setor rural tem sido fixada pelo governo abaixo do ponto de equilíbrio. Assim, o problema relevante para o intermediário financeiro é a minimização de seus custos. Porém, financiar a agricultura é uma das operações de mais alto custo no mercado financeiro em razão da dispersão geográfica - dificuldade com supervisão, recuperação de créditos, obtenção de

\footnotetext{
${ }^{3}$ Conforme Phimister (1995), Blancard et al. (2006) e Briggeman \& Morehart (2009).

${ }^{4}$ Nomeadamente, no que diz respeito à sua assimetria. Segundo Araújo (1996), esta decorre do fato de os emprestadores não possuírem o mesmo nível de informação que os tomadores a respeito das suas características e possibilidades de sucesso dos empreendimentos financiados. $\mathrm{O}$ comportamento do tomador não é perfeitamente observável por parte do emprestador.
} 
informações etc. - dos problemas com garantias, do pequeno tamanho dos empréstimos e dos riscos inerentes à atividade rural.

Essa série de fatores acaba por elevar a exigência dos agentes financeiros na concessão dos créditos, limitando a confiança no tomador de crédito, o que influencia negativamente a oferta de crédito rural.

Segundo Hoff \& Stiglitz (1993), no mercado de crédito, a informação assimétrica está associada principalmente a dois problemas: a seleção adversa e o risco moral. A seleção adversa acontece devido aos tomadores (agentes) conhecerem melhor sua capacidade de saldar a sua dívida, ao contrário do emprestador (principal). Porém, a capacidade de pagamento difere entre os tomadores. Nesse caso, as instituições, cobrando a mesma taxa de juros de todos os emprestadores, acabam por atrair também aqueles "menos qualificados", ou seja, algumas propostas de mais alto risco e, consequentemente, com maior probabilidade de inadimplência. Esse processo pressiona no sentido de uma elevação nas taxas de juros, o que atrai, cada vez mais, tomadores de baixa qualidade, e assim por diante. O limite desse processo seria a própria inviabilização do mercado.

Segundo Araújo (1996), a seleção adversa leva a um comportamento racionador de crédito por parte do emprestador, desde que não exista regulamentação para obrigatoriedade de concessão de empréstimo. Isso pode até mesmo ser visto como uma possível explicação para a ausência de trabalhos sobre informação assimétrica no Brasil, uma vez que o crédito formal sempre foi fortemente regulamentado desde a criação do SNCR. Já o risco moral ${ }^{5}$ está ligado a decisões que podem ser tomadas após as partes terem firmado o contrato de cessão de crédito. Se a taxa de juros está diretamente relacionada ao risco do projeto, após o empréstimo, o tomador pode ter atitudes na execução que aumentem o risco do projeto e isso pode ser considerado, pois estas ações não são completamente observáveis pelo emprestador.

A grande evidência da existência do problema de assimetria de informação no Brasil, principalmente no que tange ao crédito rural, encontra-se nos dados do Banco Central $\left(\mathrm{BACEN}^{6}\right)$ e do Instituto de Pesquisa Econômica Aplicada $\left(\right.$ IPEA $\left.^{7}\right)$. Segundo o BACEN, no ano de 2006 estavam disponíveis mais de $\mathrm{R} \$ 43$ bilhões de recursos aprovados para o crédito, porém, apenas $\mathrm{R} \$ 26,44$ bilhões foram contratados. Esse dado reforça que existem fatores causadores da restrição ao uso de crédito rural por fatores associados à seleção adversa ou ao risco moral, uma vez que grande parte do total de recursos aprovados pelo BACEN não tem sido contratada ao longo dos anos, ainda que mais de dois milhões de produtores rurais estejam sem crédito.

\footnotetext{
${ }^{5}$ Segundo Stadler \& Castrillo (2001), podem-se verificar duas situações no risco moral: 1) Informação oculta (situação em que um agente mantém alguma informação relevante em segredo do principal, já que esta informação pode ser comprometedora para o seu cadastro junto à instituição, o que colocaria em risco a liberação do financiamento); e 2) Ação oculta (as ações do agente não são observáveis e nem verificáveis, ou seja, o principal não pode avaliar a ação em qualidade ou quantidade).

${ }^{6}$ Banco Central do Brasil (2006)

${ }^{7}$ http: //www. ipeadata.gov.br
} 


\section{Aspectos Teóricos e Metodológicos}

\subsection{O Modelo Teórico}

O modelo identifica os efeitos que uma restrição de crédito causa na utilização dos recursos. ${ }^{8}$ Para tal, assume-se que o produtor maximiza o seu consumo em dois períodos, sendo 0 o período inicial e 1 o período final, que será expresso Inter temporalmente por uma função utilidade aditiva. Nesse caso, a função utilidade é representada por:

$$
U=\left(c_{0}, c_{1} ; z^{p}\right)
$$

Em que o parâmetro $c_{0}$ representa o consumo no período 0 e $c_{1}$, no período 1 e $z^{p}$ é um conjunto de variáveis exógenas que representam as características dos produtores.

A produção agrícola exige um financiamento inicial com gastos em insumos no período 0 , enquanto a colheita ocorre no período 1 . Para atender a suas necessidades de liquidez nos primeiros gastos, o produtor pode tomar um empréstimo de capital de giro $\mathrm{K}$ no período 0 , que deve ser reembolsado no período 1. A possibilidade de produção do produtor é representada pela segunda derivada da função de produção côncava, conforme (2):

$$
y=f\left(x, z^{y}\right)
$$

em que $x$ representa os insumos, com preço $p$, que necessitam de um financiamento inicial (por exemplo, sementes, fertilizantes etc.) e que está sujeito, portanto, a uma restrição de liquidez. Outras variáveis que representam insumos foram omitidas para simplificar a demonstração. Insumos fixos exógenos, como terrenos e maquinários, são representados por $z^{y}$. O produtor tem uma restrição orçamentária em cada período, e pode ter uma restrição de crédito no período 0 . O orçamento no período 0 é constituído por dotações iniciais com fundos de liquidez $E$, um montante do crédito emprestado $K$, e transferências públicas exógenas $T$. Pressupõe-se que todos os parâmetros sejam negativos. No equilíbrio, a soma dessas variáveis será igual ao gasto das variáveis que representam a quantidade de insumos mais consumo. Já a renda no período 1 será composta por receitas provenientes da produção $y$, que no equilíbrio é igual ao reembolso do crédito emprestado no período 0 mais o consumo no período 1 . $K(1+r)$ é o reembolso do crédito, sendo $r$ a taxa de juros.

Existe na literatura uma rica investigação sobre as causas do racionamento do crédito bem como potenciais contramedidas. Segundo Stiglitz \& Weiss (1981), o crédito pode ser limitado por problemas não resolvidos de seleção adversa ou risco moral, devido à assimetria de informação sobre o mercado de crédito. A probabilidade de que a restrição esteja vinculada a um produtor diminuirá com o aumento da disponibilidade de sinalização e/ou a existência de algum dispositivo de rastreio para superar a assimetria de informação existente. $^{9}$

Uma forma simples de inserir a restrição de crédito no modelo para produtores agrícolas é assumir um limite superior representado por $\bar{K}\left(z^{p}, z^{y}\right)$ sobre

\footnotetext{
${ }^{8}$ Singh et al. (1986), apresentam detalhamento das diferentes abordagens estáticas para a análise de restrição de crédito.

${ }^{9}$ Para uma análise teórica detalhada, consultar o trabalho de Diamond (1989).
} 
o crédito que os produtores podem obter. $\mathrm{O}$ valor desse limite dependerá das características dos produtores e da produção $z^{h}$ e $z^{y}$. Dessa forma, o problema do produtor agrícola pode ser representado pelo seguinte esquema de equações:

$$
\begin{gathered}
\max U\left(c_{0}, c_{1} ; z^{p}\right) \text { em relação a } c_{0}>0, c_{1}>0, x>0 \text { e } K \geq 0, \text { sujeito a } \\
\left.E+K+T-c_{0}-p x=0 \text { (restrição orçamentária no período } 0\right), \\
\left.f\left(x ; z^{y}\right)-c_{1}-(1+r) K=0 \text { (restrição orçamentária no período } 1\right) \mathrm{e} \\
\bar{K}\left(z^{p}, z^{y}\right)-K \geq 0(\text { restrição do crédito no período } 0) .
\end{gathered}
$$

A restrição do crédito pode ou não existir. ${ }^{10}$

As condições de primeira ordem da solução ótima são as derivadas do Lagrangeano em relação a todas as variáveis de decisão e o multiplicador de Lagrange. Pelo fato de (5) ser uma desigualdade, devem-se utilizar as condições de Kuhn-Tucker:

$$
\begin{gathered}
\frac{\partial L}{\partial c_{0}}=\left[\frac{\partial U(\bullet)}{\partial c_{0}}\right]-\eta=0 \\
\frac{\partial L}{\partial c_{1}}=\left[\frac{\partial U(\bullet)}{\partial c_{1}}\right]-\lambda=0 \\
\frac{\partial L}{\partial x}=\left[\frac{\partial U(\bullet)}{\partial x}\right]-\eta p=0 \\
\frac{\partial L}{\partial K}=\eta-\lambda(1+r)-\mu=0 \\
\frac{\partial L}{\partial \mu}=\bar{K}\left(z^{p}, z^{y}\right)-K \geq 0, \mu\left(\frac{\partial L}{\partial \mu}\right)=0
\end{gathered}
$$

As equações (6) e (7) representam o consumo ótimo; (8), a produção ótima; e (9), a demanda por crédito. As equações (3), (4) e (10) são as condições marginais que devem ser satisfeitas por uma solução ótima. $\eta$, $\lambda$ e $\mu$ são os multiplicadores de Lagrange.

Para demonstrar o impacto que a restrição de crédito causa na produção, usam-se as soluções anteriores, caso não exista a restrição de crédito, ou seja, $\mu=0$, substituímos então (9) em (8) quando $\mu=0$ rendimentos:

$$
\frac{\partial f(\bullet)}{\partial x}=p(1+r)
$$

${ }^{10}$ O Lagrange utilizado para resolver o problema da produção-consumo é:

$$
\begin{aligned}
L= & U\left(c_{0}, c_{1} ; z^{p}\right)+\eta\left(E+K+T-c_{0}-p x\right) \\
& +\lambda\left[f\left(x ; z^{y}\right)-c_{1}-(1+r) K\right]+\mu\left[\bar{K}\left(z^{p} ; z^{y}\right)-K\right]
\end{aligned}
$$


Esta é idêntica à regra de alocação padrão, exceto que o preço dos insumos deve ser corrigido pela taxa de juros, e pelo fato de as despesas serem devidas a um período anterior às receitas, pode-se nessa equação representar esses insumos por $x_{s c}^{*}$. A equação (11) é independente da função de utilidade ou de quaisquer características dos produtores, o que demonstra a separação entre as escolhas de produção e de consumo, dada a não existência da restrição creditícia. Porém, no sistema do produtor, a renda total é determinada pelas decisões da produção a partir do lucro da propriedade. Isso ocorre porque o comportamento da produção afeta o consumo (mas o inverso não acontece), sendo dessa forma o modelo do produtor sem a restrição de crédito chamado de modelo recursivo (Singh et al. 1986, p. 20).

Caso exista uma restrição ao crédito, será mantida a igualdade em (5), assim, teremos $\bar{K}\left(z^{p}, z^{y}\right)$. A partir de (10), tem-se como consequência imediata, $\mu>0$. A ligação entre as restrições orçamentárias de ambos os períodos e da restrição de crédito dada pela equação (9) passa a assumir a seguinte forma:

$$
(1=r)=\left(\eta-\frac{\mu}{\lambda}\right)
$$

Resolvendo a partir de $\eta$ e substituindo na equação (8), rearranjando, temse,

$$
\frac{\partial f(\bullet)}{\partial x}=\left[(1+r)+\frac{\mu}{\lambda}\right] p
$$

em que $\mu$ e $\lambda$ são os multiplicadores de Lagrange associados respectivamente à restrição dos empréstimos no período 0 e à restrição orçamentária no período 1. Assume-se que cada um dos multiplicadores de Lagrange seja estritamente positivo, e o valor presente do custo de oportunidade dos insumos ótimos para a restrição de crédito ao produtor-consumidor (que será representado por $x_{c c}^{*}$ ) seja maior que o valor presente do custo de oportunidade encontrado na equação (5).

Desde que $x_{c c}^{*}$ tenha um valor presente do custo de oportunidade maior que o de $x_{s c}^{*}$, sendo a função de produção côncava, deve-se manter $x_{s c}^{*}>x_{c c}^{*}$. Esta é a causa de a restrição do crédito dos produtores-consumidores diminuir a quantidade de x para aumentar o valor do produto marginal. Portanto, a produção do produtor-consumidor com restrição de crédito é menor que a produção do produtor-consumidor sem a restrição creditícia. Assim como a produção, o consumo é impactado negativamente pelas restrições de crédito. Um produtor-consumidor com restrição de crédito terá uma utilidade marginal do consumo menor que sua contraparte sem a restrição.

Segundo Petrick (2004), a influência da restrição de crédito, impactando tanto a produção quanto o consumo, quebra o pressuposto de separabilidade das decisões de consumo e produção e, portanto, não se pode estimar uma forma reduzida da função de oferta de produção sem contabilizar as características do produtor e da produção. Petrick estimou o impacto da restrição do crédito na produção a partir de um modelo de Heckman de dois estágios. No seu modelo, o primeiro estágio é um modelo probit que mostra se o produtor tem ou não alguma restrição ao crédito, já o segundo estágio é uma estimativa da forma reduzida da função oferta que representa as características tanto do produtor como da produção. Outros trabalhos usaram métodos semelhantes, como Jappelli (1990), que estimou o impacto do crédito com restrição no consumo de famílias não agrícolas. 


\subsection{O Modelo Analítico}

A estimativa apresentada na equação (14) abaixo foi realizada a partir de um modelo Probit, ${ }^{11}$ em que a presença do crédito, ou sua restrição, são determinadas por algumas características observáveis dos estabelecimentos rurais. Nesse caso, as características observáveis no modelo estão associadas ao parâmetro $z^{p}$ presente na função utilidade do produtor, apresentada na equação (1) da seção 2.1. O modelo Probit irá gerar os Propensity Scores, que representam a possibilidade de os estabelecimentos receberem o crédito rural ou terem restrição a ele. A partir das estimativas dos Propensity Scores, será utilizado o Matching para subdividir a amostra em quatro grupos, sendo que dois destes grupos gerados, dadas suas características observáveis, teriam a mesma possibilidade, tanto de receber o crédito, como de ter restrições a ele.

Após o procedimento de Matching, serão utilizados alguns indicadores para verificar se os estabelecimentos que receberam o crédito rural tiveram melhor desempenho em comparação aos estabelecimentos que tiveram restrição, baseando-se apenas nos grupos equiparáveis. A possibilidade de o produtor ter crédito pode ser avaliada pelo seguinte modelo estocástico:

$$
\begin{aligned}
k_{i}^{*} & =\beta_{0}+\beta_{1} \text { lvprod }_{i}+\beta_{2} \text { area }_{i}+\beta_{3} \text { lgasto }_{i}+\beta_{4} \text { idade }_{i}+\beta_{5} \text { idade }_{i} \\
& +\beta_{6} \text { tde }_{i}+\beta_{7} \text { educ }_{i}+\beta_{8} \text { resid }_{i}+\beta_{9} \text { dividas }_{i}+\beta_{10} \text { internet }_{i} \\
& +\beta_{11} \text { coop }_{i}+\beta_{12} \text { prepsol }_{i}+\beta_{13} \text { irrig }_{i}+\beta_{14} \text { ortec }_{i}+\beta_{15} \text { sexo }_{i} \\
& +\beta_{i} D_{i}+u_{i}
\end{aligned}
$$

$k_{i}^{*}$ é uma variável latente que denota a demanda por crédito. Nesse caso, $k_{i}$ é uma variável dicotômica $(1,0)$ indicando se a observação $i$, nesse caso o estabelecimento rural possui o crédito ou tem restrição. As variáveis explanatórias (tais como as características dos produtores e da produção) estão especificadas logo abaixo, os $\beta_{s}$ são os parâmetros do modelo, e $u_{i}$ é o termo de erro aleatório. Cada grande região brasileira terá uma estimação específica.

$\mathrm{Na}$ Tabela 1 encontram-se todas as variáveis utilizadas para a estimação do modelo Probit.

O modelo (14) será estimado por um modelo Probit binário, onde serão gerados os Propensity Scores. Ciaian et al. (2010) trabalharam a restrição de crédito a partir de um modelo de maximização de lucro, proposto por Blancard et al. (2006). Em seus resultados empíricos, Ciaian et al. (2010) mostraram que a produtividade é afetada positivamente pelo crédito, enquanto a área e o número de trabalhadores não sofrem mudanças significativas na presença do crédito. Apesar de trabalharem com um modelo de restrição de crédito, os autores preferiram utilizar $\pi=1$ como referência à presença de crédito, ou seja, a ausência de uma restrição. Assim como em Jappelli et al. (1998), será empregado nessa pesquisa um método direto para avaliar se uma família possui ou não restrição ao crédito. E depois de classificados, comparam-se os resultados, avaliando o impacto que a restrição causa na produtividade da terra e do trabalho por meio do estimador propensity score matching, que será abordado na próxima seção.

\footnotetext{
${ }^{11}$ Em muitas aplicações, não parece fazer diferença a utilização de um modelo logit ou probit. Os valores obtidos no Count $R^{2}$ e no percentual de acerto e de erro de cada modelo para cada região foram muito semelhantes, tornando indiferente o uso do probit ou do logit. Optou-se pelo uso do modelo probit pela comodidade de o mesmo já estar implantado do algoritmo de Greedy, facilitando a aplicação do mesmo.
} 
Tabela 1: Descrição das variáveis utilizadas na Pesquisa

\begin{tabular}{|c|c|c|}
\hline Variável & Nomenclatura & Descrição \\
\hline$k_{i}^{*}$ & Acesso a crédito & $\begin{array}{l}\text { Trata-se de uma variável binária indicando se o produ- } \\
\text { tor recebeu }=1 \text { ou não }=0 \text { o crédito rural, excluindo-se as } \\
\text { pessoas que não precisaram de crédito no ano de } 2006 \text {. }\end{array}$ \\
\hline lvprod $_{i}$ & Valor da Produção & Valor total da produção no ano de 2006. \\
\hline area $_{i}$ & $\begin{array}{l}\text { Total da area produtiva } \\
\text { (ha) }\end{array}$ & $\begin{array}{l}\text { É usado como indicador do volume de riqueza que pode } \\
\text { ser usado como garantia e que desempenha papel funda- } \\
\text { mental em função do problema de assimetria de informa- } \\
\text { ção. }\end{array}$ \\
\hline lgasto $_{i}$ & Gasto com insumos & $\begin{array}{l}\text { É uma medida dos custos de produção dos estabeleci- } \\
\text { mentos. }\end{array}$ \\
\hline idade $_{i}$ & $\begin{array}{l}\text { Idade da pessoa que di- } \\
\text { rige o estabelecimento }\end{array}$ & $\begin{array}{l}\text { Tem a finalidade de captar o nível de experiência da pes- } \\
\text { soa que dirige o estabelecimento. }\end{array}$ \\
\hline idade $2_{i}$ & & $\begin{array}{l}\text { Idade ao quadrado da pessoa que dirige o estabeleci- } \\
\text { mento. }\end{array}$ \\
\hline$t d e_{i}$ & $\begin{array}{l}\text { Tempo que dirige o esta- } \\
\text { belecimento }\end{array}$ & $\begin{array}{l}\text { Dummy que capta se a pessoa responsável pelo estabele- } \\
\text { cimento rural está há mais de dez anos à frente do esta- } \\
\text { belecimento. É uma variável que procura também captar } \\
\text { experiência. }\end{array}$ \\
\hline$e d u c_{i}$ & $\begin{array}{l}\text { Grau de instrução do di- } \\
\text { rigente }\end{array}$ & $\begin{array}{l}\text { Dummy que capta se o dirigente do estabelecimento pos- } \\
\text { sui ensino superior. }\end{array}$ \\
\hline resid $_{i}$ & Residentes & $\begin{array}{l}\text { Número de pessoas que residem no estabelecimento ru- } \\
\text { ral. }\end{array}$ \\
\hline dividas $_{i}$ & $\begin{array}{l}\text { Dummy indicando se } \\
\text { possuia dividas }\end{array}$ & $\begin{array}{l}\text { Variável que ajuda na escolha do banco se determinado } \\
\text { produtor irá ou não receber o crédito rural. }\end{array}$ \\
\hline internet $_{i}$ & Acesso a internet & $\begin{array}{l}\text { Dummy que identifica se o estabelecimento tem acesso à } \\
\text { internet: nesse caso, é usado como medida do fluxo de } \\
\text { informações que o produtor rural possui. }\end{array}$ \\
\hline $\operatorname{coop}_{i}$ & Cooperativa & $\begin{array}{l}\text { Dummy que indica se o estabelecimento é associado a al- } \\
\text { guma cooperativa. }\end{array}$ \\
\hline prepsol $_{i}$ & Preparação do solo & $\begin{array}{l}\text { Dummy que capta uma variável qualitativa do solo, indi- } \\
\text { cando se o indivíduo faz preparação do solo. }\end{array}$ \\
\hline irrig $_{i}$ & Irrigação & $\begin{array}{l}\text { Assim como prepsol, a dummy identifica se o estabeleci- } \\
\text { mento rural pratica irrigação do solo. }\end{array}$ \\
\hline ortec $_{i}$ & Orientação Técnica & $\begin{array}{l}\text { Dummy que capta se o estabelecimento possui algum } \\
\text { tipo de orientação técnica. }\end{array}$ \\
\hline $\operatorname{sexo}_{i}$ & Sexo & $\begin{array}{l}\text { Sexo da pessoa que dirige o estabelecimento. }(1=\text { ho- } \\
\text { mem, } 0=\text { mulher }) \text {. }\end{array}$ \\
\hline$D_{i}$ & Dummies Regionais & $\begin{array}{l}\text { Dummy regional, nesse caso corresponde aos estados de } \\
\text { cada região pesquisada (no caso do modelo para o Brasil } \\
\text { representa as regiões brasileiras). }\end{array}$ \\
\hline
\end{tabular}

\subsection{A Avaliação de Impacto por Meio do Propensity Score-Matching}

O Propensity Score Matching é uma técnica para determinação de quase-experimentos, baseada em algoritmos de pareamento de indivíduos pertencentes a grupos distintos com o objetivo de se julgar os efeitos de um determinado tratamento. A técnica consiste na realização de um modelo Probit sobre a variável de classificação das observações e posterior utilização das probabilidades estimadas $\left[\phi\left(X^{\prime} \beta\right)\right]$ para a formação do grupo de controle. Conforme observado por Dehejia \& Wahba (2002), trata-se da inferência em amostras com viés de seleção em unidades não experimentais onde somente algumas unidades no grupo não experimental são comparáveis às unidades que tiveram o tratamento.

Neste trabalho, a aplicação da técnica de matching resultará na construção de quatro grupos distintos: 
a) Estabelecimentos rurais beneficiários do financiamento de crédito que não possuem características em comum com outro estabelecimento (Beneficiários Singulares);

b) Estabelecimentos rurais beneficiários do crédito que possuem características em comum com outros estabelecimentos não beneficiários na amostra (Beneficiários Não Singulares);

c) Estabelecimentos rurais não beneficiários do crédito rural que possuem características em comum com outros estabelecimentos beneficiários na amostra (Não Beneficiários Não Singulares);

d) Estabelecimentos rurais não beneficiários do crédito rural que não possuem quaisquer características em comum com outros estabelecimentos beneficiários na amostra (Não Beneficiários Singulares).

A análise posterior do matching será feita por meio do teste de comparação de médias e se concentrará nos estabelecimentos do grupo (b) e (c), ou seja, na "comparação de estabelecimentos rurais comparáveis".

Formalmente, considerando a realização de um experimento, em que $i$ representa a população de interesse, sendo $Y_{1 i}$ o valor da variável de interesse quando a mesma unidade $i$ está sujeita à aplicação do tratamento e $Y_{0 i}$ o valor da variável de interesse quando a unidade está sujeita à aplicação de um controle ou ausência de tratamento, o efeito do tratamento $(\tau)$ para uma unidade é definida por $\tau=Y_{1 i}-Y_{0 i}$ e o efeito esperado do tratamento em toda a população será identificado por:

$$
\left.\tau\right|_{T=1}=E\left(\tau_{i} \mid T_{i}=1\right)=E\left(Y_{1 i} \mid T_{i}=1\right)-E\left(Y_{0 i} \mid T_{i}=1\right)
$$

Em que $T_{i}=0,1$, significa que a mesma unidade experimental está sendo submetida ao controle e ao tratamento.

Conforme indicado por Dehejia \& Wahba (2002), o problema fundamental em situações não experimentais é que se pode estimar $E\left(Y_{1 i} \mid T_{i}=1\right)$. Porém, não é possível obter $E\left(Y_{0 i} \mid T_{i}=1\right)$ e a diferença $\tau^{b}=E\left(Y_{1 i} \mid T_{i}=1\right)-E\left(Y_{0 i} \mid T_{i}=0\right)$ é um estimador viciado para $\tau$. Uma vez que as unidades de tratamento e controle diferem sistematicamente em suas características, observar $Y_{0 i} \mid T_{i}=0$ não estima corretamente $Y_{0 i}$ para o grupo de controle. $\mathrm{O}$ objetivo da realização de um experimento é prevenir esse viés, no entanto, conforme apontado, através da utilização de um conjunto de covariáveis, de tal forma que $\left(Y_{1 i}, Y_{0 i}\right) \perp T_{i} \mid X_{i}, \forall i$, sendo $Y_{i}=T_{i} Y_{1 i}+\left(1-T_{i}\right) Y_{0 i}$ e a independência entre os grupos seja simbolizada por $\perp$. Dada a probabilidade de uma unidade $i$ ser submetida ao tratamento, definida como $P\left(X_{i}\right)=\operatorname{Pr}\left(T_{i}=1 \mid X_{i}\right)=E\left(T_{i} \mid X_{i}\right)$, conforme demonstrado por Dehejia \& Wahba (2002), o valor da variável de interesse $Y_{0 i}$ e $Y_{1 i}$ será independente da aplicação do tratamento, ou em outros termos, $\left(Y_{1 i}, Y_{0 i}\right) \perp T_{i} \mid p\left(X_{i}\right), \forall i$. O estimador $\tau^{b}=E\left(Y_{1 i} \mid T_{i}=1\right)-E\left(Y_{0 i} \mid T_{i}=0\right)$ torna-se não viciado para $\tau$, condicionalmente à probabilidade de inclusão no tratamento, $P\left(X_{i}\right) \equiv \operatorname{Pr}\left(T_{i}=1 \mid X_{i}\right)$.

Como é extremamente raro encontrar uma outra observação com exatamente a mesma probabilidade de inclusão no grupo de tratamento, define-se um critério de proximidade mínima de forma que a proposição $\left(Y_{1 i}, Y_{0 i}\right) \perp$ $T_{i} \mid X_{i}, \forall i$ seja válida. $\mathrm{O}$ critério definido como a distância métrica em Dehejia \& Wahba (2002)) é dado por: 


$$
d(i, j)=\left|p\left(X_{j}\right)-\left(\frac{1}{|j|}\right) \sum_{j \in J} p\left(X_{j}\right)\right|
$$

O matching com o vizinho mais próximo. ${ }^{12}$

Seja $T$ o conjunto de unidades que receberam o tratamento e $C$ um conjunto de unidades de controle, sejam $Y_{i}^{T}$ e $Y_{i}^{C}$ as respostas observadas das unidades que receberam o tratamento e das unidades do grupo controle, respectivamente, e $C(i)$ o conjunto de unidades do grupo controle "pareadas" com as unidades do grupo de tratamento, tendo um escore estimado dado por $p_{i}$, o pareamento com o vizinho mais próximo escolhe $C\left(p_{i}\right)=\min \left|p_{i}-p_{k}\right|$, que constitui um pareamento único para cada unidade do tratamento, a menos que exista mais de um vizinho com o mesmo escore. Na prática, a ocorrência de múltiplas vizinhanças constitui um caso raro, particularmente se o vetor de características X contiver variáveis contínuas (Becker \& Ichino 2002).

No casamento através de um raio $r$ temos:

$$
C\left(p_{i}\right)=\min \left\{\left(p_{j}|| \mid p_{i}-p_{k} \|<r\right)\right\}
$$

em que todas as unidades que tenham a diferença entre os escores $p_{i}$ e $p_{j}$ menor que um raio $r$ são pareadas.

Em ambos os métodos, vizinhança mais próxima e pareamento radiano, representadas por $N_{i}^{C}$ as unidades do grupo de controle pareadas $(i \in C)$, e definido por $w_{i}=\frac{1}{N_{i}^{C}}$, se $j \in C(i)$ e $w_{i}=0$, caso contrário. Então, o efeito do tratamento em ambas as formulações é dado por:

$$
\begin{aligned}
\tau^{M} & =\frac{1}{N^{T}} \sum_{i \in T}\left[Y_{i}^{T}-\sum_{i \in C} w_{i j} Y_{i}^{C}\right]=\frac{1}{N^{T}}\left[\sum_{i \in T} Y_{i}^{C}-\sum_{i \in T} \sum_{j \in T} w_{i j} Y_{j}^{C}\right] \\
& =\frac{1}{N^{T}} \sum_{i \in T} Y_{i}^{C}-\frac{1}{N^{T}} \sum_{j \in C} w_{j} Y_{j}^{c}
\end{aligned}
$$

em que os pesos $w_{j}$ são definidos por $w_{j}=\sum_{i} w_{j}^{2} \operatorname{var}\left(Y_{j}^{C}\right)$. A variância será dada por:

$$
\operatorname{var}\left(\tau^{M}\right)=\frac{1}{\left(N^{T}\right)^{2}}\left[\sum_{i \in T} \operatorname{var}\left(Y_{i}^{T}\right)+\sum_{i \in C} w_{j}^{2} \operatorname{var}\left(Y_{j}^{C}\right)\right]
$$

O efeito do tratamento dado pelo estimador de Kernel será obtido através de:

$$
\tau^{K}=\frac{1}{N^{T}} \sum_{i \in T}\left[Y_{i}^{T}-\frac{\sum_{i \in C} Y^{C} G\left[\frac{\left(p_{j}-p_{i}\right)}{h_{n}}\right]}{\sum_{k \in C} G\left[\frac{\left(p_{k}-p_{i}\right)}{h_{n}}\right]}\right]
$$

em que $G(\bullet)$ é uma função kernel.

\footnotetext{
${ }^{12}$ O IBGE permite que os microdados sejam trabalhados apenas com o software SAS, e tal software tem algumas limitações no que tange as rotinas Propensity Score-Matching. Existe, somente o método de Greedy que trabalha com o vizinho mais próximo e a distância de Mahalanobis. Métodos mais indicados a dados sociais como o de estratificação e o Kernel não estão internalizados no SAS.
} 


\subsection{Procedimentos, Variáveis e Fonte de Dados}

O modelo de restrição de crédito foi estimado pelo procedimento PROC LOGISTIC/SAS, com a opção link=probit lackfit, especificando uma função de ligação Probit. O matching um-para-um, realizado entre os grupos de estabelecimentos beneficiários e não beneficiários do crédito, utilizou a implementação do algoritmo de Greedy em uma Macro/SAS, disponível em Parsons (2001).

As variáveis analisadas em termos de produtividade foram construídas da seguinte forma:

Produtividade da terra Foi utilizado o valor total da produção dividido pelo total de área produtiva ${ }^{13}$ do estabelecimento rural. O valor total da produção é uma variável derivada do IBGE e é obtida pelo produto entre a quantidade produzida em 2006 e o preço médio unitário do volume $(\mathrm{kg}$, litro etc.) do produto informado.

Produtividade do trabalho Foi utilizado o valor total da produção dividido pelo número de trabalhadores empregados ${ }^{14}$ na produção.

A fonte dos dados utilizada foi o Censo Agropecuário de 2006, que tem 5,18 milhões de estabelecimentos agropecuários pesquisados em todo o Brasil, sendo que destes, cerca de 4,37 milhões pertencem à agricultura familiar. A unidade de investigação do Censo Agropecuário 2006 compreendeu toda unidade de produção dedicada, total ou parcialmente, à exploração agropecuária, florestal e/ou aquícola, independentemente de seu tamanho. Porém, dos dados trabalhados, foram excluídos os estabelecimentos que declararam não precisar de crédito rural no ano de 2006, entendendo-se que esses estabelecimentos, por não demandarem crédito, não eram afetados pelo problema da restrição.

Os estabelecimentos que faziam parte de assentamentos também foram retirados da amostra, pois se trata de estabelecimentos que possuem um aglomerado muito peculiar, existindo geralmente nesses estabelecimentos um conjunto de famílias assentadas, o que não estaria representando de certa forma um estabelecimento, mas sim, vários. Também foram deixados de fora da amostra os estabelecimentos considerados agroindústria, pois eles po deriam constituir problemas de outliers na amostra.

Todas as estatísticas descritivas dos dados analisados encontram-se na Tabela A.2 do Apêndice, os valores de Mínimos e Máximos não puderam ser inseridos pela não permissão do IBGE de estatísticas que possam identificar as unidades pesquisadas.

\footnotetext{
${ }^{13} \mathrm{O}$ termo área produtiva equivale na verdade à área em processo produtivo, que corresponde ao somatório de toda a área de lavouras, pastagens, matas e de agrossilviculturas praticadas pelo estabelecimento no ano de 2006.

${ }^{14} \mathrm{O}$ número de trabalhadores foi transformado no conceito de equivalente-homem proposto por Silva \& Kageyama (1983). Com base no trabalho desses autores, as seguintes conversões foram realizadas: para não assalariados empregados (parceiros e outra condição), uma mulher = $0,66 \mathrm{EH}$ e uma criança $=0,5 \mathrm{EH}$; para não empregados (responsável e membros não remunerados da família), uma mulher $=0,6 \mathrm{EH}$ e uma criança $=0,4 \mathrm{EH}$; e para empregados assalariados (permanentes e temporários), uma mulher $=\mathrm{um} \mathrm{EH} \mathrm{e} \mathrm{ma} \mathrm{criança}=0,5 \mathrm{EH}$.
} 


\section{Resultados e Discussão}

Foi estimado o modelo Probit de restrição de Crédito Rural para cada uma das grandes regiões brasileiras, objetivando verificar o comportamento da restrição do crédito para cada uma das regiões, bem como o comportamento da produtividade e da renda familiar. Os resultados dos efeitos marginais para cada uma das variáveis e regiões do País encontram-se na Tabela 2.

Todas as estimativas, pelo teste da verossimilhança, mostram rejeição dos modelos Probit contendo somente o intercepto e a validade de pelo menos uma das variáveis utilizadas no modelo de cada uma das grandes regiões brasileiras.

Após a estimação do modelo Probit (Tabela 2), foi realizado o teste de igualdade de média para verificar se o modelo gera resultados confiáveis para equiparação de médias. Para tal, o valor da estatística dos coeficientes do modelo deve indicar que os valores das variáveis analisadas sejam iguais, ou seja, não significativas. Para a análise das variáveis contínuas, foi utilizado o teste $t$ para equiparação de média. Para as variáveis binárias, foi utilizado o teste de McNemar para variáveis binárias independentes, conforme Sheskin (2004, p. 817-840). Os resultados das estatísticas e do teste de McNemar encontram-se na Tabela A.1 do Apêndice.

\subsection{Identificação da restrição de crédito nas regiões}

Na região Norte foram utilizadas na análise 137.784 observações da amostra total dos estabelecimentos rurais que declararam precisar de crédito rural. Desses estabelecimentos, 22.940 obtiveram o financiamento (16,65\%). Das cinco regiões analisadas, esta foi a que apresentou o pior nível de restrição de crédito, sendo que $83,35 \%$ dos estabelecimentos que demandaram crédito não o obtiveram.

O modelo da região Norte foi o único que teve sua especificação diferente das demais regiões, como pode ser observado na Tabela 2. Isso ocorreu pelo fato de o teste de McNemar, acusar que as variáveis orientações técnica (ortec) e tempo em que dirige o estabelecimento (tde) influenciavam no comportamento do modelo, não permitindo que o modelo fosse comparado nas diferenças entre as médias. Ao retirá-las, todas as variáveis que estavam na estimativa passaram a ser iguais, o que permitiu a comparação entre os resultados de diferença de médias.

Para a região Norte, os coeficientes do modelo de restrição foram muito semelhantes aos resultados encontrados para as demais regiões, porém, algumas diferenças foram observadas. O valor do efeito marginal (Tabela 2) para o sexo do responsável pelo estabelecimento foi positivo e significativo a $10 \%$, ou seja, pode-se afirmar que o fato de ser homem na região Norte aumenta a probabilidade de obter crédito rural, porém, essa probabilidade é muito baixa $(0,49 \%)$. O tamanho da área e o acesso à Internet não influenciam na probabilidade de obter crédito, indicando que a concentração e a informação não são fatores decisivos para concessão de crédito aos estabelecimentos rurais.

O valor da produção possui um efeito marginal positivo, bem como o número de pessoas residentes no estabelecimento. As dívidas têm efeitos marginais negativos sobre a probabilidade de obter crédito: possuir dívidas reduz a probabilidade de obter o crédito em 20,43 pontos percentuais. Já duas das variáveis que verificam a qualidade do solo diminuem a probabilidade de ob- 


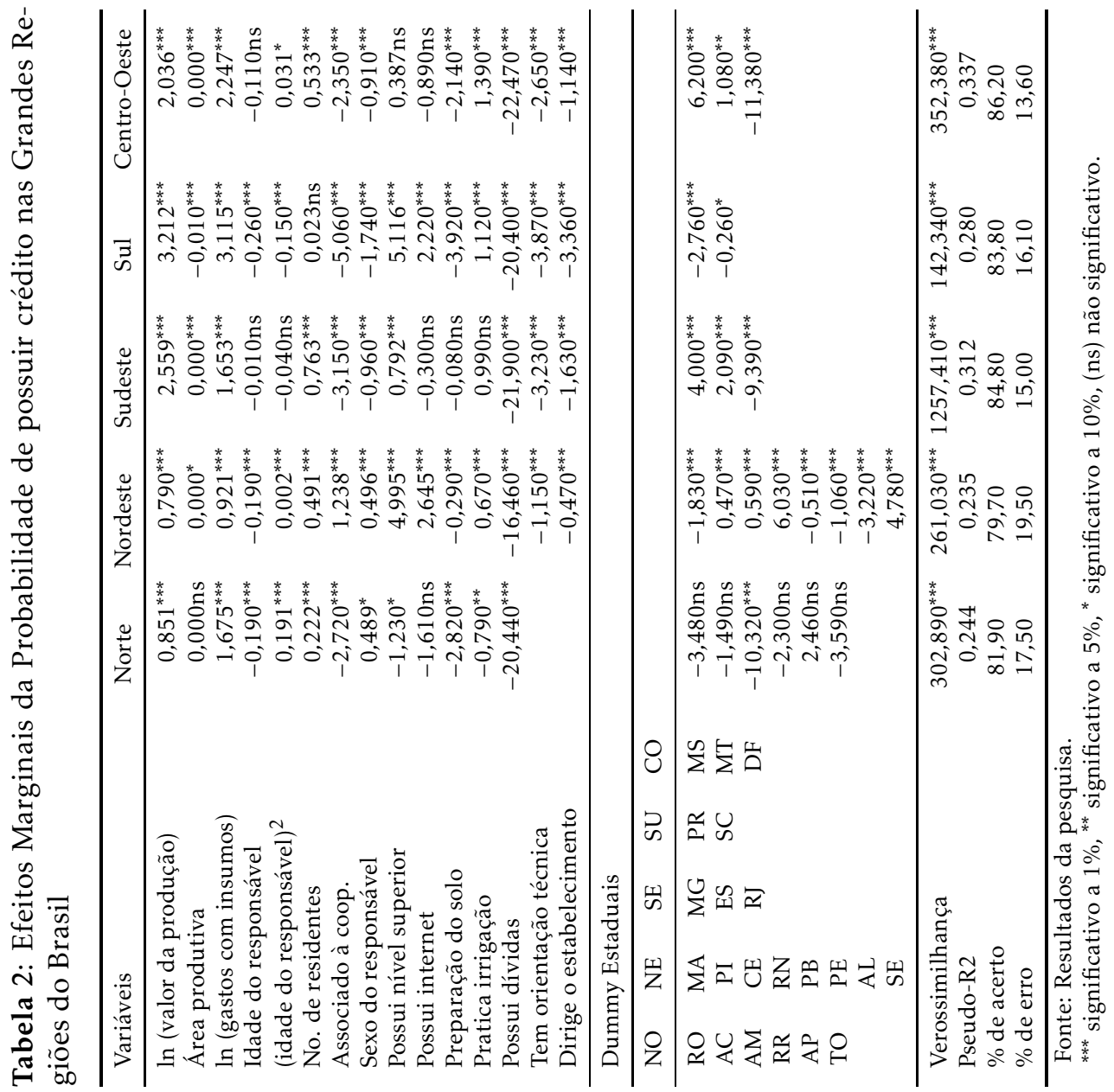


ter crédito: tanto a preparação do solo como a irrigação têm efeitos marginais negativos. Uma razão para que isso ocorra pode ser verificada em Souza Filho (2004), que, analisando o Censo Agropecuário de 1995/96, verificaram que na região Norte a maior parte dos agricultores familiares faz pouco uso de tecnologias mecânicas no manejo do solo. Essas características são explicadas pelas condições edafoclimáticas da região, provocando uma menor utilização de recursos como irrigação.

Os valores médios de produtividade encontrados após o procedimento encontram-se na Tabela 3.

Nenhum dos valores médios encontrados foi significativo para a região, portanto, observa-se que a política de crédito rural não exerce nenhuma influência na produtividade da região Norte. O que se percebe é uma aplicação não eficiente dos recursos públicos na região, algo que já foi observado por Silva et al. (2009), tanto para a região Norte quanto para o Centro-Oeste no que tange a aplicação dos Fundos Constitucionais. Ou seja, é um resultado próximo de que recursos do crédito tenham comportamentos semelhantes nessa região.

Partindo para a região Nordeste, a Tabela 2 evidencia que o fato de fazer parte de uma cooperativa e de ser do sexo masculino aumenta a probabilidade do produtor em obter crédito rural. Mesmo com o maior percentual de mulheres entre as regiões analisadas, a região não apresentou uma característica observada nas outras regiões, em que uma maior proporção de estabelecimentos que tinham mulheres como dirigentes tinham maior probabilidade de obter o crédito. Comparados ao estado da Bahia, os estabelecimentos localizados no Maranhão, Paraíba e Pernambuco possuem probabilidade menor de obter crédito, enquanto Piauí, Ceará, Rio Grande do Norte e Sergipe possuem probabilidades maiores de fazer parte da política de crédito.

Ao realizar o procedimento de Greedy com os 228.325 estabelecimentos na região que alegaram ter acesso ao crédito rural, obteve-se um novo conjunto de estabelecimentos agora totalizando 345.198, sendo 172.554 beneficiados com o crédito e a mesma quantidade em estabelecimentos gêmeos não beneficiados. Foram perdidos, com isso, 55.681 estabelecimentos dos 228.325 no procedimento de matching. Quanto à efetividade da política de crédito, observa-se que na região a diferença entre as médias da produtividade da terra de quem é beneficiário do crédito e de quem é não beneficiário foi positiva e significativa, ou seja, a política de crédito rural na região Nordeste teve impacto positivo e significativo a 5\%, conforme a Tabela 3.

Os estabelecimentos que receberam crédito tiveram um volume de produtividade da terra de $\mathrm{R} \$ 570,84$ por hectare de área produtiva, maior que os não beneficiados pelo crédito. Esse resultado é contrário ao encontrado por Magalhães (2006), que fizeram a análise para o estado de Pernambuco. No entanto, considerando toda a região Nordeste, verifica-se efeito positivo da política de crédito rural. Deve-se frisar que os autores direcionaram a análise apenas para o Pronaf, ou seja, a agricultura comercial pode ter um desempenho mais favorável no aumento da produtividade na região, comparada à política de crédito do Pronaf.

Outro aspecto que pode justificar o resultado positivo do crédito é sua menor concentração interna, pois, segundo dados do Anuário Estatístico do Crédito Rural (Relatório 5131), o Nordeste possuía, no ano de 2006, 49\% do número de contratos de crédito rural. Ou seja, um maior número de estabe- 


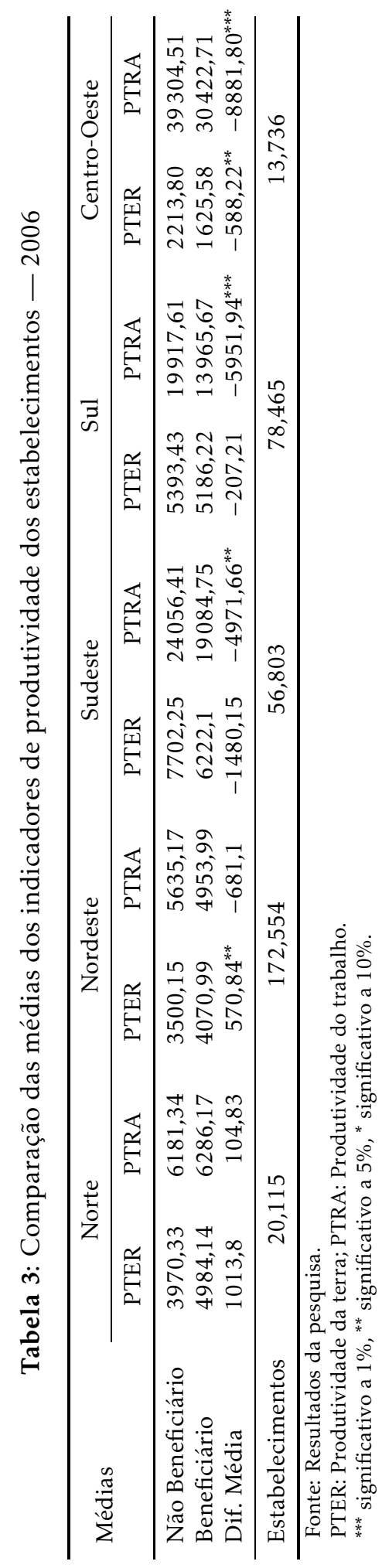


lecimentos recebe o crédito indicando uma maior dispersão do crédito nessa região do país.

O indicador de produtividade do trabalho não teve significância estatística, indicando, portanto, não efetividade neste aspecto da política de crédito aos estabelecimentos da região. As evidências para a região Nordeste seguem um comportamento já observado para todo o universo considerado. Um fator que pode explicar o não efeito da política de crédito na região pode ser um possível efeito vizinhança ou parentesco, ou seja, propriedades rurais beneficiadas pelo crédito teriam informações e incentivos para o cultivo em novas áreas próprias, deixando as propriedades de trabalho originais. ${ }^{15}$

Focando-se na análise da região Sudeste, o modelo de restrição de crédito (Tabela 2) indica que o comportamento das variáveis diferiu em alguns efeitos marginais comparados a outras regiões analisadas. A variável idade, idade 2, internet e se realiza preparação do solo não foram significativas, indicando que elas não ajudam a explicar alterações na probabilidade de obter crédito na região Sudeste. O interessante é observar que na região com a maior importância econômica do país a variável que capta a informação (se tem acesso à internet) não tem impacto significativo. Como nas demais regiões, a região Sudeste indicou que, pelo fato de ser homem e de fazer parte de uma cooperativa, os efeitos marginais são negativos, conforme observado na Tabela 2.

Observou-se também efeito marginal negativo para os estabelecimentos cujo responsável estivesse mais de dez anos à frente da direção do estabelecimento (tde) como também para os estabelecimentos possuidores de orientação técnica. Já a variável irrigação indica que os estabelecimentos que praticam essa técnica têm aumento na sua probabilidade de obter crédito.

Apesar de a experiência não aumentar a probabilidade para obtenção do crédito, ter nível superior (educ) eleva a probabilidade, mostrando esse resultado que na região o responsável pelo estabelecimento não precisa ser experiente, mas ter nível superior ajuda o estabelecimento a fazer parte de uma política de crédito.

Pelo matching um-para-um, observa-se que dos 113.086 estabelecimentos que receberam crédito, foram encontrados 56.803 estabelecimentos beneficiados pela política de crédito, e outros 56.803 estabelecimentos gêmeos não beneficiados, ou seja, dos estabelecimentos que receberam crédito na região Sudeste, foram perdidos 56.283 por não terem encontrado um estabelecimento com as mesmas características observáveis. A Tabela 3 mostra os resultados das diferenças das médias entre as produtividades.

$\mathrm{O}$ indicador de produtividade da terra para a região Sudeste foi negativo, porém, não significativo, levando a concluir que a política de crédito não afetou a produtividade da terra na região Sudeste no ano de 2006. Assim como a produtividade da terra, a produtividade do trabalho apresentou valor negativo. A produtividade do trabalho dos beneficiários do crédito rural foi menor em $\mathrm{R} \$ 4.971,66$ por trabalhador, ou seja, mesmo com o acesso ao crédito, os estabelecimentos rurais beneficiados não conseguiram ser mais produtivos no trabalho que os estabelecimentos que tiveram algum tipo de restrição.

Analisando os efeitos marginais do modelo de restrição de crédito para a região Sul pela Tabela 2, todos os seus coeficientes apresentaram um compor-

\footnotetext{
${ }^{15}$ Isso significa que poderia estar ocorrendo algum tipo de efeito espacial entre os estabelecimentos, no qual o crédito poderia não estar afetando apenas o estabelecimento beneficiado, mas também o seu entorno.
} 
tamento do efeito marginal semelhante aos resultados dos sinais das outras regiões. Apenas o coeficiente do número de residentes não foi significativo, enquanto os demais foram significativos a $1 \%$.

A idade do dirigente do estabelecimento reduz a probabilidade de obter crédito na região Sul, bem como o tempo em que dirige o estabelecimento, indicando que a experiência não é um fator determinante para aumentar a probabilidade de ter acesso ao crédito rural. Já a informação possuir internet e o fato de o dirigente ter curso de nível superior aumentam a probabilidade de obter crédito na região Sul. Ter dívidas e orientação técnica, bem como fazer algum tipo de preparação do solo, diminuem a probabilidade de obter crédito rural.

Pelo coeficiente das variáveis regionais, observa-se que os estabelecimentos que fazem parte do estado do Paraná e de Santa Catarina têm uma probabilidade menor de obter crédito que os estabelecimentos oriundos do estado considerado um dos maiores produtores brasileiros, que é o Rio Grande do Sul.

Quanto ao resultado do modelo Pós-Matching, observou-se que a região Sul foi a que mais perdeu estabelecimentos após o pareamento, pois, dos 279.236 $(68,42 \%)$ estabelecimentos que receberam crédito, apenas 78.465 participaram do processo (nesse caso para beneficiários e não beneficiários do crédito), o que totalizou 156.930 estabelecimentos na análise comparativa de diferença de médias como pode ser observado na Tabela 3.

Ainda pela análise da Tabela 3, todos os indicadores foram negativos, porém a produtividade da terra não foi significativa. Dessa forma, conclui-se que para a região Sul o crédito rural não surtiu efeito na produtividade da terra, tanto que as médias dos beneficiários e não beneficiários do crédito apresentam valores muito próximos. A produtividade do trabalho tem uma diferença significativa, e para os estabelecimentos que não receberam crédito, essa diferença é de aproximadamente $\mathrm{R} \$ 6$ mil por trabalhador, indicando que um fenômeno semelhante ao observado na região Sudeste estaria acontecendo na região Sul do país.

Finalmente no Centro-Oeste o modelo de restrição de crédito observado na Tabela 1 apresentou um bom ajuste. E entre os modelos analisados, foi o que apresentou o maior nível do pseudo R2, 0,337, apresentou o maior nível de acertos, de $86,20 \%$, e 27.302 dos 82.257 estabelecimentos analisados receberam crédito rural.

Os coeficientes de idade do responsável pelo estabelecimento, se o responsável pelo estabelecimento possuía nível superior e se o estabelecimento possuía acesso à internet, não foram significativos. O efeito marginal desses coeficientes (Tabela 2) mostra que a probabilidade de obter o crédito na região é nula.

Na região, o fato de fazer parte de uma cooperativa e o responsável pelo estabelecimento ser uma homem diminuem a probabilidade. Os resultados negativos nos efeitos marginais foram observados também para as variáveis orientação técnica, realizar alguma técnica de preparação do solo e o responsável pelo estabelecimento ter experiência. Como nas demais regiões, as dívidas são um empecilho para ter acesso ao crédito no Centro-Oeste.

O maior nível de gastos com insumos na produção eleva a probabilidade de obter o crédito, bem como o maior número de pessoas residentes no estabelecimento. O fato de praticar o processo de irrigação contribui positivamente na região para a probabilidade de obter o crédito rural. 
Os estabelecimentos dos estados do Mato Grosso e Mato Grosso do Sul têm maiores probabilidades de obter crédito quando comparados ao estado de Goiás, isso ocorre pelo fato de essas regiões terem desenvolvido um maior nível de expansão da agropecuária nos últimos anos. Entretanto, a capital federal tem menor probabilidade de obter crédito.

Pelo pareamento do matching para os grupos considerados gêmeos, foram encontrados 27.472 estabelecimentos, dos quais 13.736 estão no grupo dos beneficiados, tendo o mesmo número de observações sido enquadradas também como não beneficiados. Somente o valor da renda familiar não foi significativo, já a produtividade da terra e a do trabalho indicaram que os estabelecimentos não beneficiados tiveram valores maiores, conforme a Tabela 3.

$\mathrm{O}$ valor médio da produtividade da terra para os estabelecimentos que receberam crédito rural foi menor em $\mathrm{R} \$ 588,22$ quando comparado aos estabelecimentos que não receberam crédito. Para a produtividade do trabalho, a diferença foi de $\mathrm{R} \$ 8.881,80$ por trabalhador. O resultado da diferença das médias da produtividade do trabalho apresentado na região Centro-Oeste foi o maior encontrado entre as regiões brasileiras, tal resultado alto ocorrendo pela própria característica da região de utilizar um volume maior de equipamentos agrícolas, segundo Souza Filho (2004). Essa região, juntamente com a região Sul, foi uma das que apresentaram maior percentual de utilização de força mecânica (39,8\%), segundo resultados do Censo Agropecuário de 1995/96.

A partir dos resultados encontrados, observou-se que, em termos de produtividade da terra, não existe diferença entre os beneficiários e não beneficiários do crédito para as regiões Norte, Sudeste e Sul. Portanto, o fato de possuir o crédito rural não criou mudanças significativas para o conjunto de estabelecimentos beneficiados no ano de 2006. Tais resultados não ocorreram como o esperado, pois os trabalhos de Petrick (2004), Guirkinger \& Boucher (2008), Briggeman \& Morehart (2009) e Ciaian et al. (2010) mostram que a restrição de crédito acaba gerando queda no valor da produção dos produtores rurais. No caso deste estudo, era esperado que a presença do crédito aumentasse a produtividade da terra, pois, como o crédito tende a aumentar o valor da produção, esperava-se que os estabelecimentos beneficiados pela política tivessem um efeito positivo, e não nulo como foi apresentado.

Um caso a parte foi encontrado na região Nordeste, em que o efeito do crédito na produtividade da terra foi positivo, indicando que a política de crédito foi efetiva no ano de 2006 nessa região do país. Nesse caso, o resultado está de acordo com o esperado pela teoria de que o crédito formal tende a aumentar a produção (monetária) dos produtores rurais. A lei 11.322 é um aspecto que pode explicar os resultados positivos de produtividade para a região Nordeste. Segundo o CNA (2007), essa lei trata da renegociação da dívida dos pequenos produtores rurais da região da Agência de Desenvolvimento do Nordeste (Adene), beneficiando principalmente os produtores que possuíam dívidas com o BNDES e o Pronaf.

A região Centro-Oeste apresentou um resultado à parte, contrário ao que era esperado. A produtividade da terra dos estabelecimentos que tiveram a restrição do crédito foi $\mathrm{R} \$ 588,22$ maior que a dos estabelecimentos que receberam o crédito rural. Um fato relevante que pode explicar os resultados negativos e nulos da produtividade da terra para as regiões que tiveram essa característica pode estar associado à crise pela qual a agropecuária passou entre os anos de 2004 a 2006. Segundo dados do Centro de Estudos Avançados em Economia Aplicada (Cepea), a taxa média de crescimento da agropecuária 
durante o período foi de $-3,82 \%$, em 2006 essa taxa de crescimento do setor foi de $-2,68 \%$. Segundo o CNA (2007), durante o ano de 2006, percebeuse uma queda no faturamento ou na renda dos produtores, e grande parte desses produtores $(82 \%)$ culpa a queda do preço dos produtos como principal causa da piora do nível de renda no setor. Outro problema identificado foi o aumento do custo dos insumos e a valorização do real frente ao dólar.

Entretanto, outro aspecto verificado são as reclamações de atraso por parte dos agricultores familiares no repasse dos recursos. De 2004 a 2006, ocorreram mudanças nas regras de contratação do custeio, extinção do Rural Rápido, elevação dos tetos e obrigatoriedade de contratação do Proagro Mais, impedindo a renovação automática das operações do Pronaf, em alguns casos, de sua totalidade, o que ocasionou a necessidade de contratação de novas propostas. Com todos os procedimentos burocráticos exigidos, muitos agricultores sofreram com o atraso do financiamento.

Os resultados da produtividade do trabalho não foram significativos apenas para as regiões Norte e Nordeste. Para as demais regiões, esses resultados foram significativos e mostraram que os estabelecimentos que não receberam o crédito rural (tiveram, portanto, a restrição), obtiveram uma média maior da produtividade de trabalho. Esse efeito pode estar associado ao que Ciaian et al. (2010) identificaram nos países em processo de transição na Europa Central e Leste Europeu (CEE), onde, os produtores que não possuem crédito deixam de empregar mais pessoas na atividade rural, elevando sua produtividade do trabalho.

\section{Conlusões}

Este artigo teve como principal objetivo verificar a eficácia do crédito rural no Brasil sob uma ótica regional no ano de 2006. Os micro-dados do Censo Agropecuário de 2006 apontam para uma eficácia na aplicação do crédito rural apenas na região nordeste do país no que tange a produtividade da terra. Já as regiões Sul, Sudeste e Centro-Oeste mostraram que quem obteve crédito ficou em situação pior.

Nesta perspectiva, alguns pontos podem ser lançados diante desses resultados. Em primeiro lugar, é preciso entender em que medida as políticas governamentais de concessão de crédito (como o Pronaf), podem ajudar os produtores a aumentarem sua produtividade com melhor orientação técnica (e também financeira), e com o não atraso de repasse dos recursos.

Os resultados encontrados podem ser um indício de que as políticas de crédito e as políticas públicas de crédito subsidiado devem ser mais bem monitoradas e acompanhadas para promover um melhor desempenho aos agricultores beneficiados. Além disso, as negociações entre o Ministério do Desenvolvimento Agrário e a equipe econômica do governo federal devem ser planejadas com mais antecedência, para que produtores de um grande grupo (agricultores familiares) não recebam recursos tardiamente.

Os resultados negativos para os estabelecimentos que receberam o crédito, mas não tiveram melhor desempenho que os estabelecimentos não beneficiados, não podem ser considerados um elemento que desmereça a importância da política de crédito no meio rural, pois já foi verificado que o financiamento no meio rural é importante e fundamental para o desenvolvimento do setor agropecuário no Brasil. 
Apesar das limitações, acredita-se que esta pesquisa tenha contribuído para a geração de informações relevantes para o debate sobre o crédito rural no Brasil, considerando o impacto da política de crédito rural sobre o desempenho dos estabelecimentos rurais, dada a existência de estabelecimentos com restrições creditícias captadas por um modelo de restrição de crédito. O uso da técnica econométrica, com a aplicação do Propensity Score Matching (PSM), permitiu que os estabelecimentos fossem pareados em grupos equiparáveis. Portanto, o PSM nos garante que os grupos que estão sendo comparados possuem as mesmas chances de receber ou não o crédito rural.

\section{Referências Bibliográficas}

Araújo, U. M. (1996), Assimetria de informação no crédito rural: aspectos teóricos e um modelo para classificação do risco dos créditos concedidos a cooperativas agropecuárias, Tese de doutorado, Escola Superior de Agricultura "Luiz de Queiroz", Universidade de São Paulo., Piracicaba (SP).

Assunção, J. \& Chein, F. (2007), 'Condições de crédito no brasil rural', Revista de Economia e Sociologia Rural 45(2), 367-407.

Assunção, J. J. \& Alves, L. S. (2007), 'Restrições de crédito e decisões intrafamiliares', RBE 61(2), 201-229.

Banco Central do Brasil (2006), Anuário estatístico do crédito rural, Technical report, Banco Central do Brasil, Brasília.

Becker, S. O. \& Ichino, A. (2002), 'Estimation of average treatment effects based on propensity scores', Stata Journal 2(4), 358-377.

Blancard, S., Boussemart, J.-P., Briec, W. \& Kerstens, K. (2006), 'Short- and long-run credit constraints in french agriculture: A directional distance function framework using expenditure-constrained profit functions', American Journal of Agricultural Economics 88(2), 351-364.

Briggeman, B. C., T. C. A. \& Morehart, M. J. (2009), 'Credit constraints: Their existence, determinants, and implications for us farm and nonfarm sole proprietorships', American Journal of Agricultural Economics 91(1), 275-289.

Chaves, R. A., Sanchez, S., Schor, S. \& Tesliuc, E. (2001), Financial markets, credit constraint, and investiment in rural Romania, 1 edn, Washington.

Ciaian, P., Falkowski, J. \& Kancs, D. A. (2010), Access to credit, factor allocation and farm productivity: Evidence from the cee transition economies, in '114th Seminar of European Association of Agricultural Economists'. Berlin. EAAE, April 15-16.

CNA (2007), 'Relatório de atividades 2006'.

URL: Disponivel em: <http://www.cna.org.br/cna/publicacao/down_anexo.wsp?tmp.arquivo=E22_16854relatorio2006.pdf $>$ Acesso em: 22/11/2009

Comin, A. A. \& Muller, G. (1986), Crédito, modernização e atraso, $1^{\mathrm{a}} \mathrm{edn}, \mathrm{CE}-$ BRAP. 
Dehejia, R. H. \& Wahba, S. (2002), 'Propensity score-matching methods for nonexperimental causal studies', The Review of Economics and Statistics 84(1), 151-161.

Diamond, D. W. (1989), 'Reputation acquisition in debt markets', The Journal of Political Economy 97(4), 828-862.

Guirkinger, C. \& Boucher, S. R. (2008), 'Credit constraints and productivity in peruvian agriculture', Agricultural Economics 39(3), 295-308.

Hoff, K. \& Stiglitz, J. E. (1993), 'Introduction: Imperfect information and rural credit markets: puzzles and policy perspectives', World Bank Econ. Rev. $4(3), 235-250$.

Jappelli, T. (1990), 'Who is credit constrained in the u. s. economy?', The Quarterly Journal of Economics 105(1), 219-234.

Jappelli, T., Pischke, J. S. \& Souleles, N. S. (1998), 'Testing for liquidity constraints in euler equations with complementary data sources', Review of Economics and Statistics 80(2), 251-262.

Kageyama, A. (2003), 'Produtividade e renda na agricultura familiar: efeitos do pronaf-crédito', Agricultura em São Paulo 50(2), 1-13.

Leite, S. P. (2001), 'Análise do financiamento da política de crédito rural no brasil (1980-1996)', Estudos Sociedade e Agricultura 16(abril), 129-163.

Magalhães, A. M. e. a. (2006), 'A experiência recente do pronaf em pernambuco: uma análise por meio de propensity score', Economia Aplicada 10(1), 57-74.

Magalhães, A. M. \& Filizzola, M. (2005), 'The family farm program in brazil: the case of parana', XVIII Congresso da SOBER.

Parsons, L. S. (2001), 'Reducing bias in a propensity score matched-pair sample using greedy matching techniques', Proceedings of the Twenty-Sixth Annual SAS Users Group.

URL: Disponivel em: <http://www2.sas.com/proceedings/sugi26/p214-226.pdf> Acesso em: 24/11/2009

Petrick, M. (2004), 'A microeconometric analysis of credit rationing in the polish farm sector', European Review of Agricultural Economics 31(1), 77-101.

Phimister, E. (1995), 'Farm consumption behavior in the pesence of uncertainty and restrictions on credit.', American Journal of Agricultural Economics 77(4), 952-959.

Schultz, T. W. (1965), A transformação da agricultura tradicional, 1 edn, Zahar.

Sheskin, D. (2004), Handbook of Parametric and Nonparametric Statistical Procedures, 3th edn, CRC.

Silva, A. M. A., Resende, G. M. \& Silveira Neto, R. M. (2009), 'Eficácia do gasto público: uma avaliação do fne, fno e fco', Estudos Econômicos 39(1), 89125. 
Silva, J. G. \& Kageyama, A. (1983), 'Emprego e relações de trabalho na agricultura brasileira: Uma análise dos dados censitários de 1960, 1970, 1975', Pesquisa e Planejamento Econômico 13(1), 235-266.

Singh, I., Squire, L. \& Strauss, J. (1986), Agricultural household models: extensions, applications, and policy, Baltimore: Johns Hopkins University Press.

Souza Filho, H. M. (2004), 'Agricultura familiar e tecnologia no brasil: características, desafios e obstáculos', XLII Congresso da SOBER. Cuiabá (MT).

Stadler, I. M. \& Castrillo, D. P. (2001), An introduction to the economics of information: incentives and contracts, New York: Oxford Universit Press.

Stiglitz, J. E. \& Weiss, A. (1981), 'Credit rationing in markets with imperfect information', The American Economic Review 71(3), 393-410.

\section{Apêndice A}




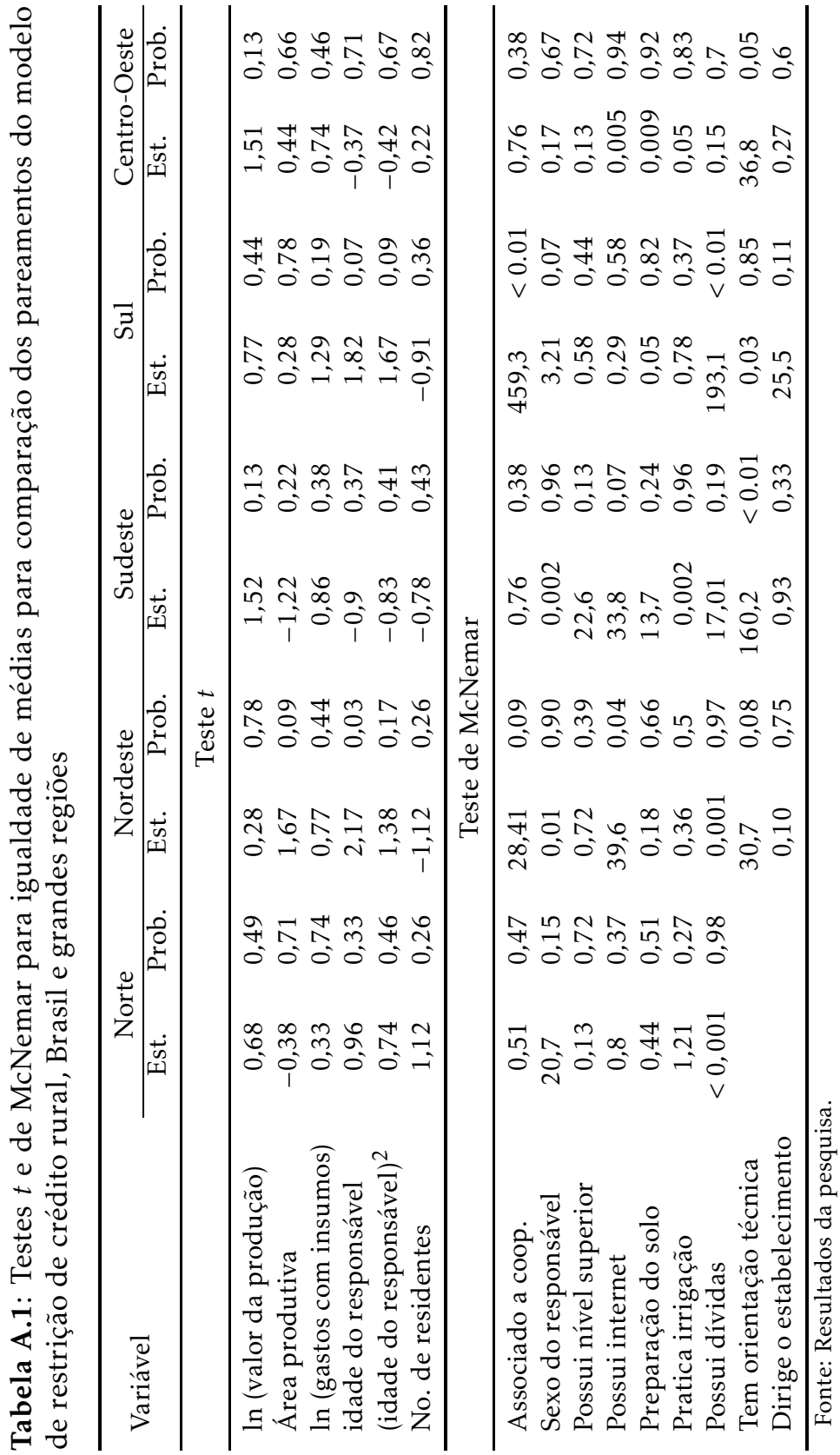


Tabela A.2: Estatísticas descritivas das variáveis contínuas e tabulações das dummies para as Grandes Regiões utilizadas no modelo de restrição de crédito

\begin{tabular}{|c|c|c|c|c|c|c|}
\hline \multirow{2}{*}{ Variáveis } & \multicolumn{3}{|c|}{ Norte $(\mathrm{N}=137.784)$} & \multicolumn{3}{|c|}{ Nordeste $(\mathrm{N}=1.070 .004)$} \\
\hline & $\mathrm{Me}$ & Md & $\mathrm{Dp}$ & $\mathrm{Me}$ & Md & $\mathrm{Dp}$ \\
\hline ln (valor da produção) & 7,96 & 8,07 & 1,73 & 6,97 & 6,92 & 1,83 \\
\hline Área Produtiva & 75,36 & 16,94 & 507,85 & 18,70 & 3,01 & 191,75 \\
\hline ln (gastos com insumos) & 5,83 & 6,61 & 3,15 & 5,40 & 5,65 & 2,31 \\
\hline idade do responsável & 47,36 & 47,00 & 14,05 & 49,55 & 49,00 & 15,23 \\
\hline No. de residentes & 2,79 & 2,00 & 2,53 & 2,06 & 2,00 & 1,96 \\
\hline Dummies & $\mathrm{N}$ & $\%$ & & $\mathrm{~N}$ & $\%$ & \\
\hline Associado a coop. & 504 & 3,66 & & 19495 & 1,82 & \\
\hline Sexo do responsável & 124986 & 90,71 & & 912058 & 85,24 & \\
\hline Possui nível superior & 159 & 1,15 & & 8215 & 0,77 & \\
\hline Possui internet & 419 & 0,30 & & 2931 & 0,27 & \\
\hline Preparação do solo & 23882 & 17,33 & & 502499 & 46,96 & \\
\hline Pratica irrigação & 4561 & 3,31 & & 7044 & 6,58 & \\
\hline Possui dívidas & 2781 & 20,18 & & 228141 & 21,32 & \\
\hline Tem orientação técnica & & & & 81619 & 7,63 & \\
\hline Dirige o estabelecimento & & & & 705595 & 65,94 & \\
\hline
\end{tabular}

Fonte: Resultados da pesquisa.

$\mathrm{N}$ = número de observações; $\mathrm{Me}=$ Média; $\mathrm{Md}=$ Mediana; $\mathrm{Dp}=$ Desvio Padrão.

Tabela A.2: Estatísticas descritivas das variáveis contínuas e tabulações das dummies para as Grandes Regiões utilizadas no modelo de restrição de crédito (continuação)

\begin{tabular}{lrrrrrr}
\hline \multirow{2}{*}{ Variáveis } & \multicolumn{3}{c}{ Sudeste $(\mathrm{N}=305.542)$} & \multicolumn{3}{c}{ Sul $(\mathrm{N}=408.112)$} \\
\cline { 2 - 8 } & \multicolumn{1}{c}{$\mathrm{Me}$} & $\mathrm{Md}$ & $\mathrm{Dp}$ & $\mathrm{Me}$ & $\mathrm{Md}$ & \multicolumn{1}{c}{$\mathrm{Dp}$} \\
\hline ln (valor da produção) & 8,57 & 8,69 & 2,13 & 9,41 & 9,55 & 1,69 \\
Área Produtiva & 44,73 & 9,68 & 280,45 & 34,21 & 10,70 & 154,12 \\
ln (gastos com insumos) & 7,85 & 7,96 & 2,36 & 8,62 & 8,70 & 1,72 \\
idade do responsável & 51,51 & 51,00 & 13,76 & 48,57 & 48,00 & 12,66 \\
No. de residentes & 1,87 & 2,00 & 1,81 & 2,25 & 2,00 & 5,70 \\
\hline Dummies & $\mathrm{N}$ & $\%$ & & $\mathrm{~N}$ & $\%$ & \\
\hline Associado a coop. & 57866 & 18,94 & & 15923 & 39,02 & \\
Sexo do responsável & 276087 & 90,36 & & 382174 & 93,64 & \\
Possui nível superior & 15599 & 5,11 & & 10514 & 2,58 & \\
Possui internet & 9788 & 3,20 & & 11964 & 2,93 & \\
Preparação do solo & 150377 & 49,22 & & 34878 & 85,46 & \\
Pratica irrigação & 48565 & 15,89 & & 23656 & 5,80 & \\
Possui dívidas & 92988 & 30,43 & & 234583 & 57,48 & \\
Tem orientação técnica & 98572 & 32,26 & & 243139 & 59,58 & \\
Dirige o estabelecimento & 207426 & 67,89 & & 286041 & 70,09 & \\
\hline
\end{tabular}

Fonte: Resultados da pesquisa.

$\mathrm{N}=$ número de observações; $\mathrm{Me}=$ Média; $\mathrm{Md}=$ Mediana; $\mathrm{Dp}=$ Desvio Padrão. 
Tabela A.2: Estatísticas descritivas das variáveis contínuas e tabulações das dummies para as Grandes Regiões utilizadas no modelo de restrição de crédito (continuação)

\begin{tabular}{lrrr}
\hline \multirow{2}{*}{ Variáveis } & \multicolumn{3}{c}{ Centro-Oeste $(\mathrm{N}=82.257)$} \\
\cline { 2 - 4 } & \multicolumn{1}{c}{$\mathrm{Me}$} & \multicolumn{1}{c}{$\mathrm{Md}$} & \multicolumn{1}{c}{$\mathrm{Dp}$} \\
\hline ln (valor da produção) & 8,82 & 8,78 & 2,20 \\
Área Produtiva & 261,40 & 38,72 & 1126,94 \\
ln (gastos com insumos) & 8,65 & 8,61 & 2,41 \\
idade do responsável & 51,06 & 51,00 & 13,21 \\
No. de residentes & 1,84 & 2,00 & 1,92 \\
\hline Dummies & $\mathrm{N}$ & $\%$ & \\
\hline Associado a coop. & 13433 & 16,33 & \\
Sexo do responsável & 75855 & 92,22 & \\
Possui nível superior & 5939 & 7,22 & \\
Possui internet & 2119 & 2,58 & \\
Preparação do solo & 35898 & 43,64 & \\
Pratica irrigação & 5733 & 6,97 & \\
Possui dívidas & 25545 & 31,06 & \\
Tem orientação técnica & 2897 & 35,22 & \\
Dirige o estabelecimento & 48182 & 58,57 & \\
\hline
\end{tabular}

Fonte: Resultados da pesquisa.

$\mathrm{N}=$ número de observações; $\mathrm{Me}=$ Média; $\mathrm{Md}=$ Mediana; Dp = Desvio Padrão. 